\title{
A dinâmica do agronegócio e seus impactos socioambientais na Amazônia brasileira
}

Luiz Guilherme Teixeira Silva - Pesquisador da Embrapa Amazônia Oriental, mestre em Geociências e Meio Ambiente pela Universidade Estadual Paulista Júlio de Mesquita Filho (UNESP, 1995), doutor em Ciências pelo Núcleo de Altos Estudos Amazônicos da Universidade Federal do Pará (NAEA) da UFPA (2007).

Adriano Venturieri - Pesquisador da Embrapa Amazônia Oriental, engenheiro agrônomo, mestre em Sensoriamento Remoto pelo Instituto de Pesquisa Espacial (INPE, 1996), doutor em Geografia pela UNESP (2003).

Alfredo Kingo Oyama Homma - Pesquisador da Embrapa Amazônia Oriental, mestre em Economia Aplicada pela UFV (1976), doutor em Economia Aplicada pela UFV (1988).

\section{Resumo}

Uma das principais características da expansão do agronegócio no país é a incorporação à cadeia produtiva de novas áreas que apresentam uma grande fragilidade socioambiental, como as áreas de cerrado e savanas amazônicas - que, do ponto de vista geográfico, correspondem a fronteiras. Sem considerar as limitações ambientais, essa expansão tem ocorrido em decorrência da pequena infraestrutura física dessas áreas e do seu isolamento em relação aos grandes centros e portos de elevada cabotagem, visto que a maioria dos produtos representa commodities e produtos da pauta de exportação no mercado global. Atualmente, a dinâmica da expansão do agronegócio e seus impactos socioambientais em diferentes sub-regiões da Amazônia ainda não são conhecidos de forma sistemática e bem fundamentada. Este trabalho apresenta uma análise dos impactos ou das mudanças estruturais - transformações - decorrentes do agronegócio na paisagem, à luz da Ecologia de paisagem, enquanto área de conhecimento que reúne duas das principais abordagens: uma geográfica, que investiga a influência do homem sobre a paisagem e a gestão do território; outra, ecológica, centrada na importância do contexto espacial para os processos ecológicos e na importância dessas relações para a conservação da integridade biológica e dos ecossistemas.

\section{Palavras-Chave}

Agricultura, agronegócios, impactos socioambiental, Amazônia.

\begin{abstract}
One of the main characteristics of the agribusiness expansion in the country is the incorporation of new areas that present a major socio-environmental fragility into the productive chain, such as the areas of the Amazon cerrado and savannas - which, from a geographic point of view, correspond to the borders. Without considering the environmental limitations, this expansion has occurred due to the small physical infrastructure of these areas and its isolation in relation to the great centers and harbors of high boatswain, seen that the majority of the products represent commodities and products of exportation agenda in the global market. Nowadays, the expansion dynamic of the agribusiness and its socio-environmental impacts in different sub-regions of the Amazonia are not known yet in a systematic way and very well founded. This work present an analysis of the impacts oro $f$ the structural changes - transformations - because of the agribusiness in the landscape, in the light of the Ecology of landscape, while area of knowledge which gathers two of the main approaches: a geographic one, which investigates the influence of man upon the landscape and the management of the territory; the other, the ecological one, centered in the importance of the special context for the ecological processes and upon the importance of these relations for the preservation of the biological integrity and ecosystems.
\end{abstract}

\section{Keywords}

Agriculture, agribusinesses, socioenvironmental impacts, Amazônia. 
A globalização e o rápido avanço da ciência e da tecnologia estão provocando um acelerado processo de mudança nas regras de competência internacional e, por conseguinte, no desenvolvimento econômico. A adoção de novas formas de produzir produtos tradicionais e a capacidade de oferecer outros novos produtos aumentam a competitividade. Todavia, a falta de acesso a novas tecnologias resulta na perda de competitividade em relação a outros países que as incorporam. Cada vez mais, observa-se que as opções baseadas em dotações de inovações relativas aos recursos naturais têm perdido importância ante as vantagens comparativas dinâmicas que se constroem mediante inversões na investigação tecnológica, nos capitais humano e social e em políticas que promovam as inovações produtivas e institucionais (ALIANZA CONTIGO, 2003). Nesse sentido, a visão de mundo e a forma com que algumas populações e grupos sociais percebem seus espaços sociais impõem limites e contenção em relação ao uso e à apropriação de bens e recursos naturais que podem ser usados em benefício próprio ou de uma coletividade (SILVA et al., 2008).

A agricultura sempre ocupou lugar de destaque seja na história econômica do Brasil, seja na constituição da nação, seja na sua formação e divisão social do trabalho, tendo inclusive sido responsável pela instalação do setor industrial do país (SILVA, 1991). Nos últimos anos, a participação do agronegócio no Produto Interno Bruto (PIB) do Brasil tem-se mantido em níveis crescentes, com uma média de 24,53\% do PIB do País (Figura 1).

Para efeitos da análise efetuada nesta apresentação, serão trabalhadas duas situações:

a) uma leitura mais acadêmica, segundo a qual o crescimento agrícola, com base no modelo de exploração de recursos, sobretudo em larga escala, praticado pelo segmento empresarial, não pode ser sustentado a longo prazo, e a percepção de que os camponeses (agricultura familiar (AF)), na agricultura tradicional, ainda que considerados racionais e eficientes na alocação dos recursos de que dispõem, não garantem uma alocação eficiente de recursos seja individualmente, seja no âmbito de comunidades rurais, dado o enorme passivo ambiental atualmente existente em suas terras;

b) uma percepção, comum à academia e aos atores locais, da urgência e da necessidade de incorporação, à base tecnológica e às instituições, de mudanças endógenas ao sistema econômico, ou seja, orientadas pelas condições de oferta de fatores e de demanda de produtos - devendo essas mudanças ser feitas de modo a facilitar a substituição de fatores relativamente escassos (mão de obra familiar e terra com floresta, caso de estudo) por fatores relativamente abundantes (e facilmente acessíveis, ou seja, terras antropizadas) na economia, o que significa dizer 
incorporação de "técnicas novas", não propriamente tecnologias, que facilitem a substituição da mão de obra por outros insumos, ou seja, técnicas "economizadoras de mão de obra", e a substituição da terra por outros insumos, como técnicas "economizadoras de terra".

Não obstante o modelo que se venha a utilizar, deve-se ter em mente que, quando se analisa o agronegócio, não basta considerar fatores puramente econômicos e a competitividade como a única orientação do modelo.

A existência de um trade off envolvendo competitividade e cooperação revela que o homem, ao ocupar a principal posição no modelo, pela sua própria condição de gestor e beneficiário do agronegócio, deve perseguir os modelos que apontem para um desenvolvimento sustentável do planeta como um todo. Nessa perspectiva, as ações devem pautar-se por uma visão em que haja maior equilíbrio entre as dimensões econômicas, sociais, políticas, ambientais e éticas (SEKIGUCHI; PIRES, 1995).

É evidente que lidar com questões complexas como a que envolve mudanças na base produtiva da agricultura familiar, como verificado em assentamentos rurais, exige um tratamento diferenciado e não pode deixar de lado a influência de fatores sociais e humanos e as dinâmicas de crescimento da população e da sociedade, além da necessária inserção e participação da AF na economia. Afinal, é iminente a passagem de uma etapa de transição, em que a expansão da área era a principal fonte de crescimento da produção agrícola mundial, para outra, em que a maior parte do crescimento da produção de lavouras e animais deve ocorrer pela elevação da frequência e da intensidade de cultivo (HAYAMI; RUT'TAN, 1980).

\begin{tabular}{|c|c|c|c|}
\hline Ano & $\begin{array}{c}\text { PIB BR } \\
\text { Em milhões de Reais (R\$) }\end{array}$ & $\begin{array}{c}\text { PIB Agronegócio } \\
\text { Em milhões de Reais (R\$) }\end{array}$ & $\begin{array}{c}\text { Participação no } \\
\text { PIB do Pais (\%) }\end{array}$ \\
\hline 1994 & $1.758,232$ & 499.675 & 28,42 \\
\hline 1995 & $2.121,668$ & 514.275 & 24,24 \\
\hline 1996 & $2.284,146$ & 505.929 & 22,15 \\
\hline 1997 & $2.355,388$ & 501.458 & 21,29 \\
\hline 1998 & $2.364,134$ & 504.364 & 21,33 \\
\hline 1999 & $2.309,650$ & 513.657 & 22,24 \\
\hline 2000 & $2.248,854$ & 514.161 & 22,87 \\
\hline 2001 & $2.249,069$ & 523.143 & 23,26 \\
\hline 2002 & $2.248,854$ & 569.220 & 25,31 \\
\hline 2003 & $2.106,589$ & 606.419 & 28,79 \\
\hline 2004 & $2.199,158$ & 621.910 & 28,28 \\
\hline 2005 & $2.295,279$ & 592.943 & 25,83 \\
\hline 2006 & $2.451,488$ & 595.626 & 24,30 \\
\hline 2007 & $2.558,822$ & 642,634 & 25,11 \\
\hline
\end{tabular}

Fonte: CEPEA 
Para efeitos da análise dos fatores que interferem na dinâmica do agronegócio em regiões de fronteira como as encontradas na Amazônia, utilizou-se como analogia a figura geométrica que define o tetraedro de silício, o qual representa o elemento fundamental da estrutura da principal classe de mineral formadora de rocha na natureza, o silicato.

As estruturas dos diferentes silicatos têm como unidade fundamental o grupo [SiO4]'Q em que, quatro “Q” ocupam os vértices de um tetraedro regular em cujo centro se encontra o Si. A partir desse tetraedro base, por união de certo número de Q de tetraedros vizinhos, constroem-se os edifícios estruturais dos diferentes silicatos. Essa união dos tetraedros pode dar-se por fusão segundo um vértice (1 Q comum), segundo dois vértices (2 Q comuns), segundo 3 ou 4 vértices, com 1, 2, 3 ou 4 tetraedros vizinhos.

$\mathrm{Na}$ figura hipotética, os vértices estariam ocupados pelos seguintes fatores determinantes do agronegócio: (1) terra, (2) infraestrutura, (3) organização e (4) vantagens competitivas, que ocupariam o lugar dos átomos de oxigênio - o agronegócio, que incluiria ainda a gestão e o homem, ocuparia o centro. Essa figura geométrica tende a assumir outra forma, combinando-se com novas unidades de tetraedro justapostas em diferentes arranjos, ou articulações, conforme a predominância de um dos fatores na realização de um negócio envolvendo determinada organização e commodities em determinado tempo e lugar. Portanto, assumiria igualmente uma dimensão territorial.

Em relação à vantagem competitiva, ela leva em consideração a conjuntura econômica, os mercados, as taxas e a estabilidade cambial, o preço de commodities, as barreiras econômicas (subsídios, tarifas alfandegárias), as taxas de juro. Esse conjunto, por sua vez, tem estreita relação com as políticas públicas e privadas praticadas pelos agentes econômicos envolvidos, para a satisfação de produtores e consumidores de produtos do agronegócio. Ao Estado, cabe o papel de oferecer políticas públicas voltadas para a promoção do desenvolvimento do setor agrícola e regional, de modo articulado à política ambiental e à política agrária, de maneira a também facilitar a consolidação do complexo produtivo, no campo e nas cidades.

As organizações, assim como são aqui destacadas no contexto do agronegócio, podem ser vistas segundo o tradicional paradigma da organização industrial, baseadas na estrutura conduta-desempenho, e também do ponto de vista de sua estratégia (PORTER, 1981).

O desempenho das organizações pode ser medido, de forma individual ou conjunta (por setor/ramo, cadeia, rede, clusters, ou outro tipo de agregação), de acordo com o nível geral das atividades, o Produto Interno Bruto (PIB) e outros 
índices que servem para avaliar e monitorar os desempenhos desejados. Esse conjunto de informações pode, portanto, servir de guia na escolha de processos decisórios das organizações, estimulando-as ou inibindo-as, numa lógica mais individualizada ou mais articulada com outras organizações (PEDROZO et al., 1995). Nesse sentido, Pedrozo et al. enfatizam a necessidade de uma abordagem interdisciplinar com ênfase "interorganizacional". Enquanto as organizações obtiverem ou projetarem resultados positivos, num nível aceitável, elas continuarão atuando e investindo em determinados produtos/ mercados. Por outro lado, em função da expansão das suas atividades para uma escala internacional/global e da complexidade da sua gestão, as organizações poderão explorar as oportunidades de trabalhar de maneira articulada.

Um outro aspecto importante a ser destacado diz respeito ao caráter subjetivo que envolve as organizações e os consumidores. Há todo um processo de identificação das necessidades ou das expectativas dos consumidores a ser seguido.

Para Kotler e Armstrong (1995), as compras dos consumidores são altamente influenciadas por características culturais, sociais, pessoais e psicológicas. Embora os profissionais de marketing não consigam controlar esses fatores, eles precisam ser levados em conta, visto que os clientes (consumidores) orientamse por necessidades e desejos e buscam satisfazê-los, alcançando o mais alto valor recebido. Esses clientes, por sua vez, compõem o mercado. O mercado é, portanto, constituído de todos os compradores reais e potenciais de um determinado produto ou serviço. Os compradores potenciais de um produto ou serviço apresentam quatro características: interesse, renda, acesso e qualificações (KOTLER; ARMSTRONG, 1995).

Por infraestrutura, entende-se a rede de transportes e de logística (fluvial, ferroviária e rodoviária), abrangendo o acesso e a distância das áreas produtoras, a rede de energia e a matriz energética, serviços, terminais modais, que representam importantes fatores locacionais que podem vir a facilitar ou a restringir a expansão do agronegócio.

$\mathrm{Na}$ logística de transporte, a aplicação de modelos matemáticos, com o uso da programação linear, no setor agroindustrial tem contribuído para a redução de custos de transporte e a otimização da produção no Brasil (PINHEIRO, 2008). Resultados de uma pesquisa elaborada por Chappelle (1977 apudSOUSA, 2000), por exemplo, mostram estudos voltados para agroindústrias do setor madeireiro. Nos últimos anos, esses modelos têm sido amplamente aplicados ao setor agroindustrial, destacando-se os trabalhos dos seguintes pesquisadores: Ferrari (2006) define um rearranjo espacial da capacidade estática de armazenamento de soja no Estado de 
Mato Grosso; Lima, Branco e Caixeta Filho (2005) propõem o melhor período e a melhor rota para o escoamento da soja com destino à exportação; Figueiredo $e t$ al. (2005) identificam a melhor alternativa para o escoamento do algodão matogrossense destinado à exportação, analisando diferentes cenários; Oliveira e Santos (2003) investigam a localização ótima de novas agroindústrias de esmagamento de soja no Mato Grosso; Sousa (2000) analisa o transporte de toras curtas de eucalipto, em São Paulo, para a eficiência econômica das empresas na redistribuição espacial de fontes de abastecimento; Martins e Caixeta Filho (1999) propõem modelos de racionalização e de uso da infraestrutura de transporte na distribuição modal no transporte de milho, soja e farelo de soja, no Paraná.

Quanto ao fator terra, divide-se em duas vertentes: uma diz respeito a sua natureza, enquanto meio em que se produzem commodities; a outra concerne a seu uso como ativo financeiro, cujo valor pode ser determinante ou restritivo para o agronegócio.

Os preços da terra rural, dentro de um determinado espaço geográfico, refletem a situação de sua estrutura de mercado, determinada pelo seu entorno socioeconômico e político. Os preços de mercado da terra rural são aqueles que os agentes econômicos utilizam como referência em qualquer decisão sobre esse recurso natural. Os preços de mercado, por exemplo, guiam os agentes econômicos particulares que atuam no mercado de terras em negócios de compra e venda; são referências para o governo em seus programas de democratização e tributação da terra rural; são utilizados pelas instituições de crédito como um parâmetro para determinar a hipoteca da terra e para direcionar o crédito rural.

Nesse sentido, os preços de mercado da terra surgem como uma variável relevante para compreender o uso que os agentes econômicos dão a esse recurso e também aparecem como um sinal a ser levado em conta pelos formuladores de políticas, quando pretendem definir uma eficiente distribuição econômica e social da terra.

Mas como estimar e descrever a dinâmica do preço da terra rural em um mercado de terras farto de imperfeições, em que o objeto a ser negociado caracteriza-se por ter oferta fixa, imóvel e concentrada? Por outro lado, a terra pode ser utilizada como fator produtivo na produção de bens agropecuários ou como ativo de reserva de valor, pois permite conservar a riqueza de um período para outro. Existe ainda regulação para seu uso (por exemplo, reserva florestal) e taxas impostas à propriedade, além de características culturais e sociopolíticas que afetam as soluções alcançadas pelo mercado.

Nesse contexto, o preço da terra rural deve sintetizar o efeito de todos os fatores que interagem em seu mercado. O propósito deste item será mostrar tanto 
do ponto de vista teórico quanto empiricamente as variáveis determinantes desse preço, que são responsáveis pela sua dinâmica. A sistematização teórica do mercado de terras teria como pano de fundo uma economia capitalista (REYDON, 1992; REYDON; PLATA, 1995). Isto é, parte-se do pressuposto de que o mercado de terras a ser estudado faz parte das Economias de Mercado como as chamou Polanyi (1980), ou, das Economias Empresariais, como denominadas por Keynes (1936).

Para Polanyi (1980, p. 81), "A economia de mercado é um sistema econômico controlado, regulado e dirigido, apenas por mercados [...]. Uma economia desse tipo se origina da expectativa de que os seres humanos se comportem de maneira a atingir o máximo de ganhos monetários". Para Keynes (1936), de forma semelhante, as economias empresariais caracterizam-se pelo fato de todas as suas trocas serem baseadas em valores monetários e de todos os proprietários de riqueza desejarem aumentá-la em termos monetários.

Nesse cenário de economias empresariais ou de mercado, os proprietários de riqueza adquirem diferentes tipos de ativos, com diferentes níveis de liquidez, para obter ganhos monetários e proteção contra as incertezas da economia capitalista. Eles procuram antever a psicologia do mercado de diferentes ativos e decide comprar aqueles que, segundo suas expectativas, proporcionarão maior retorno líquido.

A terra rural como um ativo apresenta três características importantes: a) é escassa em termos físicos e econômicos, b) é imóvel e c) é durável, já que não pode ser destruída facilmente. A terra é escassa não apenas por si mesma, mas na medida em que os produtos por ela gerados também o são. Entretanto, o fato de a terra ser um fator imóvel, que não pode ser reproduzido, com elasticidade de produção e de substituição baixa, aliado ao fato de a terra ser apropriada privadamente por alguns, favorece as condições para o estabelecimento de sua escassez econômica. Assim, tanto a geração de tecnologias para a elevação de seu rendimento físico, quanto medidas administrativas - como, por exemplo, a reforma agrária - podem alterar o grau de escassez da terra. Assume-se também que um mercado de terras forma-se somente a partir da aceitação generalizada da propriedade da terra, independentemente de sua forma, assim como das garantias da manutenção dessa propriedade.

Nesse sentido, se ocorrem mudanças na legislação ou nas garantias dadas à propriedade da terra, a sua condição de ativo torna-se relativa, fazendo com que se eleve o risco associado à sua aquisição, diminuindo tanto a sua liquidez quanto a sua taxa de capitalização e preço. Portanto, a referência sempre recairá sobre a propriedade, independentemente de sua forma, pois, em regiões ou países onde a 
propriedade não é formalmente estabelecida, mas é socialmente aceita, os negócios ocorrem normalmente. Portanto, há um mercado de terras, o que decorre do fato de que até mesmo a propriedade deve ser compreendida como parte de uma convenção (REYDON, 1992).

Destarte, o preço da terra enquanto ativo seria o resultado das negociações entre compradores e vendedores no mercado de terras, no qual o negócio sempre é realizado quando o comprador tem expectativas mais elevadas sobre os ganhos futuros daquela terra do que o vendedor. Consequentemente, os movimentos das expectativas sobre os ganhos futuros advindos da terra e, portanto, de seus preços são as variáveis mais importantes para compreender a dinâmica do mercado de terras (PLATA, 2001).

Em suma, a terra rural pode ser caracterizada como um ativo que, ao mesmo tempo, é de capital e líquido, negociado em uma estrutura de mercado flexível (flex price), ou seja, seu preço é determinado pela dinâmica da demanda e da oferta, porém, como a oferta de terras é considerada fixa, o preço de mercado será determinado pela dinâmica da demanda. As expectativas dos proprietários podem fixar a quantidade de terra a ser negociada, mas são as expectativas dos compradores quanto aos ganhos futuros com o uso da terra que determinarão o preço. Nesse cenário, segundo Plata (2001, p. 86), assim como para todos os ativos, o preço da terra rural deve ser determinado pelos ganhos esperados para os quatro atributos capitalizados, dados pela fórmula: $\mathbf{P}=\mathbf{q}-\mathbf{c}+\mathbf{1}+\mathbf{a}$.

Nessa fórmula, q são quase-rendas produtivas que correspondem às rendas produtivas esperadas decorrentes da propriedade da terra. $\mathrm{O}$ valor desse atributo depende dos ganhos esperados com a produção agrícola e da possibilidade de outros ganhos decorrentes da propriedade da terra, como os do crédito ou de subsídios governamentais.

c representa o custo de manutenção, ou seja, os custos esperados para manter a terra no portfolio do agente, isto é, todos os custos não produtivos da terra, como custos de transação, provisão para financiamento, quando ele é utilizado para a aquisição da terra, impostos e taxas decorrentes da propriedade.

1 é o prêmio de liquidez da terra. Refere-se à relativa facilidade de venda da terra no futuro e depende, portanto, das expectativas formadas pelos agentes em relação ao mercado de terras. É tanto maior quanto mais cresce a economia e aumenta a demanda por ativos de capital ou se houver um incremento na demanda por ativos líquidos e nas expectativas do comportamento de outros ativos líquidos que não sejam tão promissores quanto a terra.

a equivale ao ganho patrimonial da terra. Esse fluxo de renda é obtido no momento da venda da terra e depende, portanto, das condições do mercado. Esse 
atributo é normalmente incluído em q, mas, nesse caso, é importante considerálo separadamente, pois muitos compradores adquirem terras visando esse ganho. Exemplo disso seria a compra de terras da fronteira - que não necessariamente apresentam rendimento produtivo para um prazo econômico - realizada com o objetivo explícito de obter ganhos na revenda.

O mercado da terra é o espaço, não necessariamente físico, onde a terra está sendo negociada a um preço determinado em função das expectativas de ganhos do comprador e do vendedor. Nesse mercado, a terra é comprada ou vendida quando os agentes que participam do negócio esperam obter ganhos globais mais elevados do que com outros ativos. O mercado de terras brasileiro é imperfeito, pelas seguintes razões: a) há desigualdades expressivas na distribuição da propriedade da terra; b) agentes econômicos individuais podem interferir na oferta e no preço da terra; c) os sem-terra procuram-na e não têm condições econômicas de sustentar sua demanda; d) a terra não é um produto homogêneo, as propriedades têm extensões distintas, assim como são compostas de diferentes tipos e qualidades de terras. O mercado de terras será mais dinâmico se os demais mercados-produtos, trabalho e crédito - funcionarem adequadamente na região.

Para Plata (2001), a definição dos determinantes do preço da terra sempre foi e provavelmente sempre será um tema controverso e polêmico a ser destacado na literatura econômica. Segundo a sistematização teórica mostrada acima, a terra rural pode ser vista como um ativo líquido e também como fator de produção, e seu preço teria um valor presente (VP) resultante dos quatro atributos esperados indicados na equação indicada anteriormente. Isto é, o preço da terra seria obtido a partir da estimação do valor presente de todos seus fluxos de receitas líquidas futuras, como qualquer outro ativo. Mas isso não necessariamente significa que o preço de mercado (preço corrente) seja sempre igual ao valor presente das rendas futuras, pois podem existir fatores que afetam o preço de mercado e que não afetam a medida do valor presente. Na verdade, a formulação do valor presente levaria em conta apenas a tendência dos ganhos com a terra a longo prazo, deixando de lado fatos que afetam o preço da terra a curto prazo, como bolhas especulativas. Nesse sentido, o valor presente será uma função direta das rendas líquidas produtivas e uma função inversa da taxa de juros que atualizaria os fluxos de renda.

\section{METODOLOGIA}

Neste artigo foram utilizados dados e informações obtidos a partir de produtos e técnicas de geoprocessamento, sofwares, como imagens de satélite, fotografias aéreas e sobrevoos. Procurou-se definir as variáveis condicionantes 
da expansão do agronegócio e os principais cenários de expansão em escala local, a partir do ano de 2000. Para efeito de delimitação da área de abrangência, consideraram-se as seguintes sub-regiões:

a) sub-região de influência da rodovia Cuiabá-Santarém (BR-163) no entorno de Santarém (incluindo Belterra, Alenquer, Monte Alegre, Juruti, Prainha, etc.);

b) sub-região de influência da rodovia BR-158, envolvendo a sub-região que inclui os municípios de Querência, São José do Xingu, Confresa, Ribeirão Cascalheira (MT);

c) sub-região de influência da rodovia BR-158, nas cercanias das cidades de Conceição do Araguaia e Redenção (PA);

d) sub-região do sul do Amazonas, de influência do trecho da Transamazônica (BR-230) entre Humaitá e Lábrea (AM) e da rodovia do Estanho, em parte dos municípios de Humaitá, Canutama, Lábrea e Manicoré;

e) sub-região do "cone sul" de Rondônia, incluindo municípios como Vilhena, Cerejeiras, Cabixi e Colorado d'Oeste;

f) região da Terra-do-Meio, no Estado do Pará.

\section{CONCLUSÕES}

Atualmente, a dinâmica da expansão do agronegócio e seus impactos socioambientais em diferentes sub-regiões da Amazônia ainda não são conhecidos de forma sistemática e bem fundamentada. Em particular, há uma carência de estudos sobre as tendências de expansão da atividade nas paisagens amazônicas, heterogêneas em função de características dos recursos naturais (solos, topografia, hidrologia, vegetação) e da ocupação humana (situação fundiária, populações locais, atividades produtivas, etc.).

De modo geral, faltam estudos sobre a situação atual da aplicação de políticas públicas (fundiárias, ambientais, instrumentos econômicos, zoneamento, etc.) em relação a essa expansão e seus reflexos na Amazônia. Tais análises seriam particularmente relevantes para a identificação de mudanças necessárias nessas políticas, no intuito de estimular uma maior aproximação entre o agronegócio e os princípios do desenvolvimento sustentável.

Os esforços institucionais e as políticas de governo na esfera dos estados da federação no sentido de planejar o desenvolvimento a partir do ordenamento territorial -algumas iniciativas de Zoneamento Ecológico e Econômico já foram implantadas e outras estão em execução - podem não surtir os efeitos esperados se não forem acompanhados de uma efetiva regularização fundiária que permita 
facilitar o reconhecimento dos atores envolvidos em cada situação. Sem isso, dificilmente se chegará à solução dos conflitos pela posse da terra e à promoção e à expansão da atividade produtiva e do agronegócio de modo competitivo e sustentável.

\section{REFERÊNCIAS}

ALIANZA CONTIGO. Informe de Evaluación Nacional: subprograma de Investigación y Transferencia de Tecnología. México: Secretaria de Agricultura, Ganadería, Desarrollo Rural, Pesca y Alimentación; Organización de las Naciones Unidas para la Agricultura y la Alimentación, 2004.

BURT, O. Econometric modelling of the capitalization formulator farmland prices. American Journal of Agricultural Economics, v. 68, p. 10-26, 1986.

CHAPPELLE, D. E. Linear programming for forest planning. In: CONVERY, F. J.; RALSTON, C. W. (Ed.). Forestry and long-range planning. Durham: Duke University, 1977. cap. 4, p. 129-178.

FERRARI, R. C. Utilização de modelo matemático de otimização para identificação de locais para instalação de unidades armazenadoras de soja no Estado do Mato Grosso. 2006. 185 f. Dissertação (Mestrado em Economia Aplicada) - Escola Superior de Agricultura “Luiz de Queiroz”, Universidade de São Paulo, Piracicaba, 2006.

HAYAMI, Y.; RUTTAN, V. W. Agricultural development: an international perspective. Baltimore and London: John Hopkins University Press, 1980.

KEYNES, J. The general theory of employment, interest, and money. New York: Harcourt, 1936.

KOTLER, P.; ARMSTRONG, G. Princípios de marketing. 7. ed. Rio de Janeiro: Prentice-Hall do Brasil, 1995.

LIMA, L. M.; BRANCO, J. E. H.; CAIXETA FILHO, J. V. Um modelo dinâmico para otimização do escoamento de soja em grãos. In: CONGRESSO DA SOCIEDADE BRASILEIRA DE ECONOMIA E SOCIOLOGIA RURAL, 43., 2005, Ribeirão Preto. Anais... Ribeirão Preto: SOBER, 2005. p. ...-...

MARTINS, R. S.; CAIXETA FILHO, J. V. Subsídios à tomada de decisão de escolha da modalidade e ao planejamento dos transportes no Estado do Paraná. Revista de Administração Contemporânea, v. 3, n. 2, p. 75-96, maio/ago. 1999. 
OLIVEIRA, N. M.; SANTOS, H. N. Agroindústria no Estado de Matogrosso: aplicação de um modelo de localização. 2003. Disponível em: <http://www. agricultuadigital.org/critic_2004/congresso/AgriProcSIG/AgroIndustr_no_ Estado_MatoGrosso_Model_localiz.pdf>. Acesso em: 21 jun. 2005.

PEDROZO, E. A. et al. O “Sistema Integrado Agronegocial” (SIAN): uma versão interdisciplinar e sistêmica. In: WORKSHOP BRASILEIRO DE GESTÃO DE SISTEMAS AGROALIMENTARES, 2., 1999, Ribeirão Preto. Anais... Ribeirão Preto: PENSA; FEA; USP, 1999. p. 21-32.

PINHEIRO, A. M. G. S. Infra-estrutura de transporte e desenvolvimento regional sustentável: um estudo sobre o Arranjo Produtivo Local de Fruticultura do Nordeste Paraense. 2008. ...f .Tese (Doutorado em Desenvolvimento Socioambiental) - Núcleo de Altos Estudos Amazônicos, Universidade Federal do Pará, Belém, 2008.

PINHEIRO, F. A renda e o preço da terra: uma contribuição à análise da questão agrária brasileira. 1980. 270 f. Tese (Livre-Docência) - Escola Superior de Agricultura “Luiz de Queiroz”, Universidade de São Paulo, Piracicaba, 1980.

PLATA, L. E. A. Mercados de terras no Brasil: gênese, determinação de seus preços e políticas. 2001. 215 f. Tese (Doutorado em Economia) - Universidade Estadual de Campinas, Campinas, 2001.

POLANYI, K. A grande transformação: as origens de nossa época. Rio de Janeiro: Campus, 1980.

PORTER, Michael E. The contributions of industrial organization to strategic management. Academy of Management Review, v. 6, n. 4, p. 609-620, 1981.

REYDON, B. Mercados de terras agrícolas e determinantes de seus preços no Brasil: um estudo de casos. 1992. 322 f. Tese (Doutorado em Economia) Universidade Estadual de Campinas, Campinas, 1992.

REYDON, B.; PLATA, L. A ampliação do acesso a terra e o Imposto Territorial Rural. In: ENCONTRO NACIONAL DE ECONOMIA DA ANPEC, 22.,1994, Florianópolis. Anais... Florianópolis: ANPEC, 1994. 
SEKIGUCHI, C.; PIRES, E. L.S. Agenda para uma economia política da sustentabilidade: potencialidades e limites para o seu desenvolvimento no Brasil. In: CAVALCANTI, Clóvis (Org.). Desenvolvimento e natureza: estudos para uma sociedade sustentável. São Paulo: Cortez; Recife: Fundação Joaquim Nabuco, 1995. p. 208-234.

SILVA, J. G. da. Complexos agroindustriais e outros complexos. Reforma Agrária, Campinas, v. 21, n. 3, p. 5-34, set./dez. 1991.

SOUSA, R. A. T. M. e. Análise do fluxo de transporte rodoviário de toras de eucalipto para algumas indústrias de celulose e de chapas de composição no Estado de São Paulo. 2000. ... f. Tese (Doutorado em Economia Aplicada) - Escola Superior de Agricultura "Luiz de Queiroz", Universidade de São Paulo, Piracicaba, 2000. 


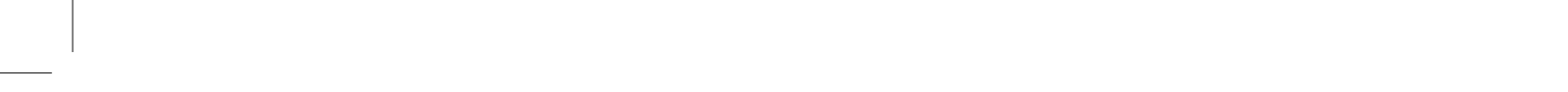

